\title{
SOCIEDADES SUSTENTÁVEIS: EM DEFESA DOS DIÁLOGOS ENTRE GERAÇÕES. UM OLHAR CRÍTICO AO DESENVOLVIMENTO SUSTENTÁVEL
}

\author{
Isabel Georgina Patronis Dominguez
}

\section{RESUMO}

Este artigo é um extrato da pesquisa na área da Educação Ambiental Crítica, a qual propõe uma reflexão sobre a importância das relações coeducativas entre gerações para sociedades mais sustentáveis. Haveria indicadores de que esses diálogos podem influenciar e, de algum modo, contribuir para a Sustentabilidade? A investigação envolveu 60 pessoas entre oito e setenta anos, no âmbito de uma Unidade de Saúde da Família, com o uso de metodologias ativas e participativas, em 30 interações educativas. O que resultou na identificação de elementos que podem influenciar a qualidade dessas relações, oferecendo contribuições para novas práticas coeducativas, além de eventualmente estimular novos estudos e interações dialógicas, levando em conta a relevância temática da intergeracionalidade e da sustentabilidade.

Palavras-chave: diálogo, intergeracionalidade, educação ambiental, comunidade aprendente, sustentabilidade.

\begin{abstract}
This article is a synopsis about an investigation in the context of critical environmental education, which proposes reflection about the importance of inter-generational educational relations in order to foster sustainable societies. Could there be evidence that these dialogues can have an effect on sustainability and contribute to it in some way? Participants of the investigations were between eight and seventy years, the educational interactions took place in a public health care center, applying participatory methodology during thirty educational activities. This way it was possible to identify elements which would be able to influence the quality of these relations, contributing new types of socio-environmental inter-generational educative practices and stimulate new investigations and dialogical interactions taking into account the topics of inter-generationality and sustainability.
\end{abstract}

Keywords: intergenerational dialogue, environmental education, learning community, sustainability.

\section{PONTOS DE PARTIDA, OS PRESSUPOSTOS DA PESQUISA E AS INQUIETUDES QUE SOBRAM}

Com o propósito de contribuir para os estudos que visem qualificar principalmente as práticas coeducativas multidisciplinares, socioambientais e populares, esta pesquisa foi apresentada para a conclusão do curso de Especialização em Educação Ambiental (EA) e Recursos Hídricos, pela USP - Universidade de São Paulo, Escola de Engenharia de São Carlos, SP, Brasil (CRHEA/USP), orientado por um professor 
doutor e uma professora doutora ${ }^{1}$, ambos da UFSCar - Universidade Federal de São Carlos, em 2013.

Seus resultados procuram animar novos encontros e processos dialógicos entre gerações, dentro e fora das escolas, sobre e para a sustentabilidade, ao subsidiá-los, fornecendo elementos que também possam se desdobrar em novas pesquisas acadêmicas, considerando a relevância temática e a carência de produção acadêmica em matéria de intergeracionalidade, ainda menos se o recorte for para a sustentabilidade.

O percurso investigativo acolheu a diferença de idades em defesa da importância da coeducação para sociedades mais sustentáveis, ancorado nos anseios por uma nova humanidade possivel e outro mundo provável, resultantes de conquistas coletivas pela democracia participativa e de justiça socioambiental, asseguradas fundamentalmente por mecanismos legítimos de controle social. As expressões escritas em itálico derivam do slogan "Outro Mundo é Possível” do Fórum Social Mundial (FSM), cujos eventos são organizados desde 2001 por movimentos sociais de todo mundo em edições anuais, com o objetivo de repensar e propor alternativas para as políticas econômicas neoliberais em contraponto aos Fóruns Econômicos Mundiais.

Foi realizado o total de 30 interações coeducativas com a presença de 60 pessoas entre oito e setenta anos. Embora essa quantidade variasse de acordo com os objetivos e características de cada atividade, além do interesse e disponibilidade das/os envolvidas/os. A presença multidisciplinar é evidente nas seguintes categorias de coparticipantes: (a) duas equipes de profissionais da Unidade de Saúde da Família (USF) localizada no jardim Jockey Clube, em São Carlos - SP; (b) gente moradora do bairro local; (c) um pequeno grupo da Graduação em Gerontologia da UFSCar; (d) alunas do programa de residência multiprofissional da UFSCar desenvolvido naquela USF; (e) além de dois orientadores engajados no processo. A maioria das interações foi realizada nas dependências ou no entorno da USF e alguns encontros nos espaços da UFSCar.

O principal ponto de partida para escrever a monografia foi repensar o rigor acadêmico no tipo de escrita, cujo texto resulta, às vezes, cansativo ou aborrecido de ler.

\footnotetext{
${ }^{1}$ A linguagem inclusiva de gênero foi adotada coerentemente à proposta freiriana, o que não significa que a use exaustivamente ao longo do texto, para que a leitura não se torne cansativa.
} 
Assim, optei pela escrita narrativa fundamentada nos estudos de Mata Martins (2011) ${ }^{2}$, os quais acenam positivamente para arriscar um pouco mais na redação, de um modo que possa ficar leve e atraente, além de contemplar e garantir a revelação e a visibilidade (no texto escrito) da pluralidade de vozes contidas no processo.

O trabalho de pesquisa envolveu três conceitos amplos e imbricados. Haveria elementos indicadores de que esses diálogos poderiam influenciar e contribuir para a sustentabilidade? E somente a caminhada com a práxis facilitou entender algo a respeito da complexidade existente nas palavras diálogos, intergeracionalidade e sustentabilidade. Posteriormente, as expressões foram adequadas em dois Pressupostos:

(1) Os diálogos e a intergeracionalidade para uma nova humanidade possível;

(2) A sustentabilidade para outro mundo, então, provável.

Por outro lado, sobraram perguntas a serem exploradas em outros estudos, algumas estão expostas a seguir.

A partir dos estudos de P. Freire (2011) e de J. Ferrigno (2003) é possível afirmar que tanto a relação dialógica é potencialmente educativa, quanto é possível a coeducação entre gerações. Então, quais são as condições necessárias e as determinantes para que o diálogo intergeracional - enquanto experiência de aprendizagem assegurada pelos autores - aconteça de fato? Que variáveis podem influenciar e comprometer o diálogo entre duas ou mais gerações?

É certo que a convivência humana é resultante da coexistência humana, ou seja, da existência simultânea em um mesmo espaço físico. Mas não são sinônimas: conviver implica desejo, intencionalidade, interesse para relacionar-se, para interatuar, algum esforço para superar os obstáculos, as diferenças, as próprias contradições (e as dos outros), para poder, então, desenvolver compreensão e harmonia, familiaridade e intimidade, solidariedade e troca, etc.; enquanto que, para a coexistência, basta alguma tolerância. No entanto, já seria suficientemente coeducativo simplesmente coexistirem duas ou mais gerações? Haveria elementos facilitadores e/ou condicionantes?

Creio que seja necessário um investimento na qualidade das interações humanas, como potencial transformador para viabilizar a utopia de outros mundos. Será que a percepção, o interesse e as opiniões sobre o meio ambiente de cada geração variam

\footnotetext{
${ }^{2}$ Artigo: A escrita narrativa e a emergência das vozes sociais: uma aposta para a valorização da alteridade no (con) texto das ciências humanas e sociais. Athenea digital, v. 11, n. 2, 2011, p. 3-15.
} 
muito? O que será que cada uma delas entende por ambiente saudável e qualidade de vida? Os compromissos assumidos de forma intergeracional podem ter maiores chances de serem cumpridos? O que, afinal, uma geração realmente pode aprender com a outra?

É possível desconstruir a ideia de que a EA deva ser feita prioritariamente com as crianças, para poder contemplar as demais gerações no processo coeducativo? Não seriam os próprios diálogos intergeracionais os desmistificadores dessa pobre ideia, mas infelizmente arraigada inclusive na cabeça de muitas/os professoras/es?

E com o exposto, se encerram os temas abertos a novas investigações.

No meu modo de entender, assegurar maior qualidade nas interações educativas entre gerações implica caminhar no ambiente de uma EA popular, crítica, dialógica, emancipatória (ou libertária), com maior possibilidade de resistência a quaisquer formas de opressão, para que as ideias de outro mundo consigam prosperar.

Costa Lima (2009) afirma que autores como Paulo Freire, Moacir Gadotti e Carlos Rodrigues Brandão (referenciados neste artigo), entre outros, fazem reflexões pedagógicas críticas e políticas que chegaram à EA brasileira por meio da Educação Popular, para combater o tradicionalismo dos projetos educativos dominantes (COSTA LIMA, 2009, p. 147).

Para Freire (2002, p. 47) é "a resistência que nos preserva vivos, na compreensão do futuro como problema e na vocação para o ser mais como expressão da natureza humana em processo de estar sendo". E esse amplo sentido freiriano de resistência e de rebeldia revolucionária ou anunciadora para a transição social só nos mostra um horizonte de caminhos e obstáculos pela frente, para nossa reumanização ${ }^{3}$.

Por exemplo, para o exercício cotidiano (consciente ou não) do comportamento "não penso, logo consumo", pode-se começar com gestos simples de contraponto aos apelos midiáticos, dizendo "redondos NÃOS" a todo o momento em que essa pobre filosofia de vida vier bater a nossa porta como sinônimo de felicidade, por que, afinal de contas, a gente pensa! E mesmo sendo bastante difícil a tarefa de sermos vigilantes conosco, pois esses momentos têm sido cada vez mais frequentes, muito

\footnotetext{
${ }^{3}$ Reumanizar in Dicionário da Língua Portuguesa com Acordo Ortográfico [em linha]. Porto: Porto Editora, 2003-2016. [consult. 2016-07-22 20:20:17]. Disponível na Internet: http://www.infopedia.pt/dicionarios/lingua-portuguesa/reumanizar?homografia=0
} 
assustadoramente por meio do marketing contemporâneo de consumo, que transforma todo ato de comprar em um verdadeiro "culto".

Todavia melhor, se envolver com iniciativas que privilegiem o coletivo, em exemplos de vivência cidadã, democrática, participativa, que podem ser educativas, prazerosas e transformadoras. Para Brandão (2005), o trabalho pode ser ainda mais fecundo quando, em uma comunidade aprendente, por exemplo, "todos têm algo a ouvir e algo a dizer. Algo a aprender e algo a ensinar. Lugares de trocas e de reciprocidades de saberes, mas também de vidas e de afetos". (BRANDÃO, 2005, p. 88).

\section{OS DIÁlOGOS ENTRE GERAÇÕES: UMA POTÊNCIA DE AÇÃO A SER REDESCOBERTA}

Os saberes freirianos nos desafiam a olhar para as coisas de um modo diferente, implica a dinâmica de olhar para o todo, para as partes, para o todo e para as partes novamente, e assim por diante, dialeticamente. Ou seja, com a presença do contraditório sempre; com a argumentação, com a confrontação, a ponderação, no uso da razão, quer seja buscando uma conciliação e/ou o surgimento de novas ideias.

Assim, esses diálogos se tornam um largo espectro de possibilidades com os saberes freirianos e as potencialidades de coeducação entre pessoas de todas as idades, defendido por J. Ferrigno (2003). Mas entender esse entrelaçamento não é algo simples, justamente se for sob a perspectiva dialógica freiriana, independentemente se intra ou entre gerações, uma vez que o diálogo cotidianamente aparece, com muita frequiência, como sinônimo de conversa ou bate papo, algo que a reduz o quase nada.

O processo dialógico freiriano deve provocar transformação interna, do entorno e da sociedade. Pressupõe atitude de respeito e aceitação das diferenças para que seja possível estabelecer relações de reciprocidade. Ele ocorre quando nos faz refletir e deixa algo dentro de nós, modificando nossas maneiras de pensar, corroborando ou refutando nossos princípios, valores, enfim, quando saímos diferentes... Nas palavras de Leonardo Boff, que abrem o prefácio do livro Pedagogia da Esperança, "toda a pedagogia de Paulo Freire é uma permanente dialogação das pessoas entre si e de todas com a realidade circundante em vista de sua transformação" (FREIRE, 2011, p. 9).

Neste sentido, a investigação exigiu, ainda, pequenas viagens em duas outras áreas: a filosófica e a sociológica, para entender algo a respeito das subjetividades e das 
intersubjetividades implícitas em toda relação humana ou relação intersubjetiva, pois condicionam suas potencialidades e intervêm na qualidade das mesmas.

No campo sociológico, Dulce Whitaker (2007, p. 51) faz um triste alerta para o fato de que a velhice "corre o risco de se transformar em estorvo", em países cujas culturas supervalorizam a juventude. Muito simpaticamente, ela fala sobre a perda de poder do idoso a partir de própria experiência, já tendo ultrapassado os 70 anos.

Com uma combinação de humor sofisticado e inteligência cativante, leveza e sabedoria, a autora se expressa de um jeito simples sobre assuntos para lá de complexos. E enfatizo essa combinação que deve resultar num jeito peculiar de falar e de escrever, porque não sei se isso seria possível na juventude ou inclusive antes da vida madura. Seria algo raro. Acho que para certos aspectos de nossa personalidade, as fronteiras da idade devem ser mais flexíveis; dependem de um arranjo imbricado com características de nossas subjetividades, resultando o que se chama maturidade.

A socióloga contribui para desestigmatizar a velhice, porque não é verdade que a pessoa idosa queira ficar em casa por ser idosa. São os espaços urbanos que não estão planejados para acolher a velhice. Ela aproveita para dar sugestões para melhorar esses espaços, tirando os véus e dando as boas-vindas aos novos atores sociais do século XXI.

Por outro lado, minha experiência entre 2005 e 2001 com a implementação do Coletivo Educador $\mathrm{CESCAR}^{4}$, igualmente demonstrou que a EA com o público jovem e adulto possui grande potencial quando se enfrentam ideias equivocadas, como: “jovens não têm interesse", "adultos não possuem tempo" ou "idosos não aprendem mais". Os resultados anunciam que é possível viabilizar a utopia de outro mundo, desde que se busquem espaços mais adequados e abordagens significativas. (OLIVEIRA, p. 107).

\footnotetext{
${ }^{4}$ A proposta faz parte do Programa de Formação de Educadoras/es Ambientais do Ministério do Meio Ambiente. Os resultados da experiência pessoal constam na publicação de três Cadernos do Coletivo CESCAR - São Carlos, Araraquara, Jaboticabal e região, dos quais sou co-organizadora.

Caderno 1 - Os fundamentos e as políticas públicas de Educação Ambiental na constituição do CESCAR. Caderno 2 - Metodologias e temas socioambientais na formação de educadoras(es) ambientais.

Caderno 3 - Sistematização das interações educativas das pessoas que aprendem participando. Disponíveis respectivamente em (acesso em 20 de junho de 2016): http://www.academia.edu/1849495/Cadernos_do_Cescar_Educa\%C3\%A7\%C3\%A3o_Ambiental_Cader no_1_

http://www.academia.edu/1849486/Cadernos_do_Cescar_Educa\%C3\%A7\%C3\%A3o_Ambiental_Cader no_2_ http://www.academia.edu/1849497/Cadernos_do_Cescar_Educa\%C3\%A7\%C3\%A3o_Ambiental_Cader no_3_
} 
Contudo, a experiência dialógica intergeracional deve ir além da presença física dos públicos de diferentes idades em qualquer proposta coeducadora. O desafio está em fazer uma conexão explícita com o temário da intergeracionalidade, evidenciando esse importante entrelaçamento, para potencializar ainda mais as ações socioambientais. Mesmo que, para a formação de coletivos educadores, já esteja implícita essa dimensão.

Evidenciar as diferentes gerações: infância, adolescência, geração adulta, meia idade e idosa - em espaços coletivos fundamentados na coeducação - pode fazer a diferença no diálogo se for possível incorporar esse aspecto, dando uma atenção mais adequada e pertinente nos momentos dialógicos (aqui-agora). A sugestão é a de destacar e aclarar a presença conjunta das diversas gerações, de modos respeitosos e criativos, mas, sobretudo, intencionalmente proativos, para agregar valor a esses encontros. Como, por exemplo, com dinâmicas que facilitem convidar as/os presentes a refletir, desmistificar preconceitos e quebrar chavões, para superar comportamentos estigmatizados, que, na verdade, são bastante frequentes em nossos cotidianos.

À luz da pesquisa, é possível afirmar que esses preconceitos estão presentes em todas as gerações, muito lamentavelmente, embora na maioria das vezes de forma muito sutil ou despercebida. Logo, explicitar a importância das ações intergeracionais deve acrescentar elementos para ampliar o entendimento de expressões, como a de que "é preciso cuidar do meio ambiente para as presentes e futuras gerações". Podendo fazer mais sentido para quem participa ao facilitar uma aprendizagem significativa, oxalá na incorporação da urgência e da necessidade da "textura intergeracional" nas redes de cuidado de nossa casa comum planetária, a serem construídas ou fortalecidas.

Nesta direção, citando o filósofo Gadamer, Hupffer (2011) corrobora a potência de ação que pode emergir da evidencia intergeracional e seu potencial dialógico:

\footnotetext{
"um diálogo solidário sobre o meio ambiente acontece quando deixou algo dentro do ser humano. Para (o filósofo) Gadamer, o diálogo com a tradição "possui uma força transformadora". Só pelo diálogo a humanidade realiza o encontro eu-tu para construir aquela espécie de comunicação que poderá dar um sentido profundo ao princípio responsabilidade intergeracional, ou seja, em deixar um ambiente ecologicamente equilibrado e uma sadia qualidade de vida para as presentes e futuras gerações". (HUPFFER, 2011, p.118).
}

\section{SUSTENTABILIDADE OU DESENVOLVIMENTO SUSTENTÁVEL, POR QUE PODE E NÃO PODE SER A MESMA COISA!}

Para o segundo eixo da pesquisa, a sustentabilidade para outro mundo provável, foi precisa uma diferenciação entre as Expressões Sustentabilidade e Desenvolvimento 
Sustentável (DS), com o intuito de ampliar a denúncia do modelo de crescimento econômico ilimitado com base na exploração humana, animal e ambiental, concomitante a anúncios de alternativas no âmbito do conceito de sustentabilidade.

A perspectiva do DS não é defendida aqui, porque, concordando com Gadotti (2012), tais propostas são distintas. Do mesmo modo que a educação não é neutra, tampouco há neutralidade nelas. $\mathrm{O}$ autor esclarece que os jogos de interesses econômicos determinam o conjunto de saberes e fazeres do DS, distorcendo aspectos da realidade para manter sua hegemonia, influenciando as práticas que reproduzem esses jogos. Os modos de reprodução podem ser desavisados ou ingênuos, mas nunca neutros!

Robinson Cavalcanti (2004, p. 38) afirma que, nesses últimos séculos, a humanidade conheceu um modelo muito perverso de produção, na organização de sua economia: o capitalismo. A nobreza foi substituída pela burguesia "como classe dominante, tendo os dominados não mais como "coisas" ou "seres inferiores", mais como mercadorias", a despeito da condição jurídica formal de "cidadãos". O autor aclara que isso ocorreu dentro de um processo de transmutação em várias etapas: "mercantil-imperial; industrial-colonial; serviços-neocolonial”, até culminar definitivamente à "globalização assimétrica, monopolista ou oligopolista, além da exploração, da exclusão de continentes, países, e fatias das populações nacionais. O poder, a propriedade e o saber são cada vez mais concentrados”.

Coerente a esse cenário histórico, Gadotti (2012) revisita dois outros estudiosos, Pérez \& Pozo, os quais afirmam que a expressão desenvolvimento sustentável converteu-se, afinal:

\footnotetext{
"num tipo de instrumento multiuso que colocou em contato ambientalistas e imobiliárias, empresários e conservacionistas, políticos e gestores, sem que pelo simples fato do uso comum do termo nada se tenha feito; muito pelo contrário, com a confusão gerada, quem mais ganhou têm sido os defensores do neoliberalismo, pois o termo desenvolvimento pode significar qualquer coisa dependendo de como se olhe e com que finalidades se empregue. Diante de uma dócil aparência de neutralidade semântica, podemos ver como seu uso polissêmico permite acepções diametralmente opostas" (GADOTTI, 2012, p. 47-48).
}

Por minha vez, fazendo em um jogo de palavras no contexto do Desenvolvimento Sustentável a partir do pensamento neoliberal, é possível dizer que se trataria de um processo globalizador de des-envolvimento intencional. 
Vejamos: o neoliberalismo defende a economia de livre mercado e a mínima intervenção do Estado, enquanto os apoiadores desse pensamento sustentam a ideia de que seja o modelo econômico mais viável para o mundo. Inclusive para alguns analistas e políticos, o único modelo exitoso que gera riqueza e bem-estar social, a despeito de vários indicadores estatísticos confiáveis que apresentam o atual aumento da pobreza, da desigualdade, da injustiça social e econômica em várias partes do mundo.

No contexto, a retórica desse tipo de DS provoca o des-envolvimento intencional ao confundir e até enganar e deixar de "envolver" concretamente as pessoas, ao longo do tempo. Tudo indica que não há um interesse legítimo (salvo exceções) de investir na promoção de mudanças estruturais no pilar econômico. Amiúde, desilude e desanima gente de boa-fé que atua em projetos ambientais locais, uma vez que os desafios são enormes e devem continuar mais adiante das iniciativas pontuais. Necessitam de inversões financeiras e implica buscar autonomia e autogestão em novas experiências de modelos socioeconômicos que nos levará à verdadeira sustentabilidade.

Os caminhos são árduos e o processo necessariamente coletivo - peregrino fraterno, forjado com o espírito participativo e colaborativo, e com as relações sociais que devem durar. Ao contrário da ideologia neoliberal, engendrada no valor monetário, no culto ao consumo, na superficialidade ou no descarte (inclusive da importância das relações humanas), na supervalorização do indivíduo, na meritocracia, ou seja, na política de competição e premiação individual pelos próprios esforços.

Depreende-se disso, que só há largos caminhos a serem explorados entre o capitalismo e outros modelos socioeconômicos no âmbito de uma possível nova ordem planetária, decerto uma nova ordem social, o que inclui impreterivelmente a dimensão econômica. $\mathrm{Na}$ atualidade, é possível apontar a existência de inúmeras iniciativas muito interessantes dentro das propostas de economia solidaria, do comércio justo ou do consumo colaborativo e da economia criativa, que se aproximam muito mais da Sustentabilidade que do DS. Todavia, deve demorar para que uma postura franca a caminho de sociedades sustentáveis sobreviva às múltiplas posturas cruelmente disfarçadas de DS. Também é possível encontrar muitos subsídios, princípios e linhas de ação para esse intento na Carta Encíclica Laudato Si ${ }^{\prime}(2015)^{5}$.

\footnotetext{
${ }^{5}$ Carta Encíclica Laudato Si', de Papa Francisco, sobre o cuidado da casa comum. Disponível em: http://w2.vatican.va/content/francesco/pt/encyclicals/documents/papa-francesco_20150524_enciclicalaudato-si.html Acesso em 10 de Julho de 2016.
} 
Mas, então, o que é sustentabilidade? - É tudo, disse uma das coparticipantes da pesquisa, de um jeito persuasivo, com os olhos brilhantes e uma expressão facial e corporal que fizeram a palavra tudo conter tudo mesmo: tudo de bom para si, para nós que estávamos numa pequena sala naquele momento, para a humanidade e o Planeta.

A palavra sustentabilidade é complexa e envolve as dimensões: ambiental, social, política, cultural, econômica e espiritual, cujos pilares são indispensáveis à permanência ou durabilidade de um local. Esses intrincados pilares de sustentação devem ser vistos juntos em suas relações, de maneira como a uma tão grande trama quanto entrelaçada é a própria teia gigante que sustenta a Vida no Planeta Terra. Não é possível separá-los. É essa forma de compreender que a diferencia radicalmente do DS.

Sustentabilidade é até hoje, na melhor das hipóteses, uma metáfora. Para mim, um grandioso mosaico conceitual incompreensível para a maioria de nós, que vive às margens de saberes de campos científicos, como o sociológico, filosófico, o teológico, o político, a psicologia social, cujos estudos são tão aprofundados quanto complicados de entender. Para Leonardo Boff (2012),

\footnotetext{
"Sustentabilidade é toda ação destinada a manter as condições energéticas, informacionais, físico-químicas que sustentam todos os seres, especialmente a Terra viva, a comunidade de vida e a vida humana, visando a sua continuidade e ainda a atender as necessidades da geração presente e das futuras de tal forma que o capital natural seja mantido e enriquecido em sua capacidade de regeneração, reprodução, e coevolução. (...) A sustentabilidade se mede pela capacidade de conservar o capital natural, permitir que se refaça e ainda, através do gênio humano, possa ser enriquecido para as futuras gerações". (BOFF, 2012).
}

Já o texto apresentado no Quadro I, não é de ninguém. Ou melhor, é de autoria coletiva sobre o que pode ser sustentabilidade, reunindo importantes aspectos deste conceito de uma forma bem simples. Foi realizado com seis coparticipantes entre 20 e 50 anos, utilizando uma dinâmica de grupo e as seguintes palavras chave relacionadas à sustentabilidade: meio ambiente, saúde, cuidado, consumo e participação comunitária. A mim coube o papel de "costurar" o diverso conjunto de manifestações e me sinto somente uma coautora agradecida à oportunidade oferecida pelas demais colaboradoras. Particularmente, o considero um importante resultado da pesquisa. 


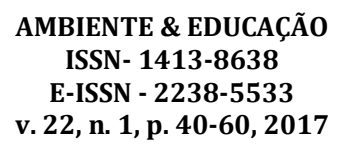

Quadro I

\section{O que pode ser Sustentabilidade}

É possivel dizer que sustentabilidade é tudo vivendo em harmonia e em equilibro dinâmico que ofereça condiçôes para uma vida feliz e com qualidade a todos os seres humanos, observando os direitos fundamentais, como para a alimentação, saúde, educação, trabalho e moradia. Faz referência ao mundo em que vivemos e às coisas necessárias para a nossa sobrevivência, e por isso é importante cuidar e preservar, sendo mais responsável pelo bemestar e por uma vida mais saudável.

Nesse sentido, a saúde é $\circ$ bem maior, e $\circ$ ato de zelar, próprio do humano, na atenção e preocupação para consigo mesmo e para com os outros. Saúde é algo que interliga tudo o que fazemos, sentimos e comemos, e quando alguma dessas vertentes vai mal, há falta de harmonia dos aspectos físicos, biológicos, psicológicos e sociais, comprometendo o bom funcionamento do organismo e a autonomia do individuo.

Sustentabilidade é tudo e todos que nos cerca e implica a sustentação e $\circ$ cuidado para com $\circ$ local em que estamos e as coisas que estão ao nosso redor, 0 ambiente inteiro e tudo $\odot$ que compore $\diamond$ espaço fisico e $\circ$ território. Nesse caso, faz referência ao local onde todos os seres vivos habitam e retiram o seu alimento para a sobrevivência, que provê oxigênio, alimentação básica e qualidade de vida, quando não há açōes ruins humanas. Mas, tudo indica, não estamos cuidando devidamente de nosso Planeta, tornando exíguos os recursos naturais disponiveis no meio ambiente.

A sociedade atual é muito consumista, atendendo aos interesses do sistema capitalista. Consumo pode ser entendido como $\circ$ uso de um bem, serviços e recursos, que deve suprir uma necessidade do indivíduo ou familia. Como, por exemplo, o consumo útil ou exagerado de alimento, energia, água, roupas e eletrodomésticos. Consumir é preciso, mas apenas $\circ$ necessário, pois sua falta (por exemplo, a falta de acesso a recursos como água e luz) ou $\diamond$ excesso de consumo são prejudiciais. Neste sentido, $\bigcirc$ ato de consumir produtos e serviços precisa ser urgentemente revisto se quisermos mais tempo de VIDA para o planeta Terra.

$O$ envolvimento das pessoas e $\circ$ exercicio coletivo podem ser mais interessantes e efetivos para enfrentar esse problema, uma vez que a participação comunitária é imprescindivel para se alcançar a almejada sustentabilidade. A adesão e a participação das comunidades, assim como as sugestz̃es e $\odot$ engajamento das pessoas para $\circ$ bem comum, podem fazer aquela diferença, onde as opiniôes e as ações são solidárias.

É certo que $\odot$ envolvimento das comunidades para $\odot$ planejamento de ações e atividades voltadas à preservação do local depende da vontade e da disponibilidade de cada indivíduo. E essa disposição ainda é mínima, infelizmente, mas isso vem mudando, pois é muito importante para quem participa e para $\circ$ beneficiário, proporcionando bem-estar e suporte social e emocional. Faz bem para $\circ$ individuo, para $\circ$ coletivo e ao ambiente. E, talve $z$ por isso mesmo, $\circ$ exercício coletivo seja fundamental para que as ações se fortaleçam, floresçam e se multipliquem.

Sustentabilidade tem a ver, afinal, com $\circ$ cuidado, num amplo sentido de entendimento da palavra. 0 cuidado é tão elementar quanto imprescindivel, seja nas ações, na fala ou com outrem e com o meio ambiente, na doação de algo ou do tempo e atenção de alguém. $O$ cuidado com a saúde - que não quer dizer ausência de doença significa, acima de tudo, também observar, proteger e preservar $\circ$ meio ambiente, na perspectiva da promoção das condições de vida humana, com boas condições ambientais, cujas preocupações e atenção favoreçam e resulte qualidade de vida e desenvolvimento integral para todos os seres vivos, humanos e não humanos, numa cultura do cuidado essencial para com a Vida na Terra.

Quadro I - Texto Coletivo de pessoas entre 20 e 50 anos, coparticipantes da pesquisa de Especialização em Educação Ambiental e Recursos Hídricos - CRHEA/USP, realizada por Isabel G. Patronis Dominguez, em 2013. O texto poderá ser utilizado como fragmento gerador de novos diálogos e reflexốes sobre o tema, mantendo a fonte. 
No cerne das expressões sustentabilidade e desenvolvimento sustentável se encontra ao menos outro grande e imbricado tema: o conceito de globalização, ou melhor, de planetarização, tal como apresentada por Gadotti (2012).

A realidade da globalização faz toda a diferença no modo de ser e do fazer humano, no modo de estar e de se relacionar, de pensar e, com distinção, no modo de fazer ciência, numa estrita interdependência das dimensões econômica, política, social, cultural, ambiental e espiritual.

Porém, coincidindo com vários especialistas na área socioeconômica, o que verdadeiramente está globalizada é a economia que condiciona as relações de poder estabelecidas entre estados e nações, muito lamentavelmente. Em outras palavras, o processo de globalização atual tem tudo a ver com a manutenção do distanciamento dos povos - ideia contrária à de aproximação - com um impedimento intencional de sua autonomia, de acordo com os interesses econômicos globalizados.

Gadotti (2012) procura distinguir "uma globalização competitiva de uma possível globalização cooperativa e solidária que, em outros momentos, chamamos de processo de planetarização":

\begin{abstract}
"a noção de cidadania planetária (mundial) sustenta-se na visão unificadora do planeta e de uma sociedade mundial. Ela se manifesta em diferentes expressões: "nossa humanidade comum", "unidade na diversidade", "nosso futuro comum", "nossa pátria comum". Cidadania planetária é uma expressão adotada para expressar um conjunto de princípios, valores, atitudes e comportamento que demonstram uma nova percepção da terra como uma única comunidade. Frequentemente associada ao "desenvolvimento sustentável", ela é muito mais ampla do que essa relação com a economia. Trata-se de um ponto de referência ético indissociável da civilização planetária e da ecologia" (GADOTTI, 2012, p. 30).
\end{abstract}

Outros temas igualmente importantes aos caminhos que nos levará à construção de Sociedades mais sustentáveis, como a saúde ambiental e a justiça ambiental ${ }^{6}$, a biotecnologia e a bioética, o poder da mídia e a influência dos meios de comunicação de massa, as dimensões do tempo e da espiritualidade, também aparecem na narrativa

\footnotetext{
${ }^{6}$ A Saúde Ambiental e a Justiça Ambiental, embora estejam garantidas na Constituição Federal de 1988, ainda precisam de mecanismos legais regulatórios e de controle social para a urgente capilaridade por meio de divulgação massiva, fazendo valer, de fato, a lei.
} 
original da pesquisa ${ }^{7}$, como braços para essa construção, os quais ajudaram a contextualizar, na pesquisa, o papel importante dos diálogos intergeracionais.

Finalmente, para o que NÃO é sustentabilidade, o artigo de Oded Grajew (2013) é suficientemente esclarecedor, referindo-se aos outros quatro pilares (ambiental, social, político e cultural), além do econômico:

\begin{abstract}
"A sustentabilidade e a insustentabilidade se tornam claras quando traduzidas em situações práticas. Esgotar recursos naturais não é sustentável. Reciclar e evitar desperdícios é sustentável. Corrupção é insustentável. Ética é sustentável. Violência é insustentável. Paz é sustentável. Desigualdade é insustentável. Justiça social é sustentável. Baixos indicadores educacionais são insustentáveis. Educação de qualidade para todos é sustentável. Ditadura e autoritarismo são insustentáveis. Democracia é sustentável. Trabalho escravo e desemprego são insustentáveis. Trabalho decente para todos é sustentável. Poluição é insustentável. Ar e águas limpos são sustentáveis. Encher as cidades de carros é insustentável. Transporte coletivo e de bicicletas é sustentável. Solidariedade é sustentável. Individualismo é insustentável. Cidade comandada pela especulação imobiliária é insustentável. Cidade planejada para que cada habitante tenha moradia digna, trabalho, serviços e equipamentos públicos por perto é sustentável. Sociedade que maltrata crianças, idosos e deficientes não é sustentável. Sociedade que cuida de todos é sustentável". (GRAJEW, 2013)
\end{abstract}

\title{
O TRATADO DE EDUCAÇÃO AMBIENTAL PARA SOCIEDADES SUSTENTÁVEIS E RESPONSABILIDADE GLOBAL COMO PANO DE FUNDO.
}

Quero evidenciar a presença deste importante documento ${ }^{8}$ na narrativa monográfica, com o propósito de "dialogar" com a revisão bibliográfica, a práxis e os resultados da pesquisa. Embora, para mim, não devesse faltar como referencial teóricoprático em quaisquer pesquisas na área da educação socioambiental crítica. Tanto pela relevância de um "Tratado" planetário, há mais de 20 anos apoiando ações educativas, inspirando a criação de ONGs e redes de EA, quanto pelo fato de subsidiar as políticas públicas em nível nacional e de alguns estados e municípios, desde então.

Ademais, esse Tratado é um inquestionável referencial teórico específico e, conjuntamente, um exemplo de vivência para a dimensão da intergeracionalidade, por ter sido construído de modo coletivo ao longo de um ano de trabalho realizado com pessoas de vários países, contando com a colaboração de educadoras/es de adultos, jovens e crianças de oito regiões do mundo. Um pequeno documentário nos conta um pouco a respeito dessa construção e pode ser encontrado, juntamente com os 16

\footnotetext{
7 A íntegra da narrativa monográfica está sendo revisada para publicação em forma de Ensaio em português e espanhol. ${ }^{8}$ Disponível em: http://www.mma.gov.br/port/sdi/ea/deds/pdfs/trat_ea.pdf Acesso em junho 2016.
} 
princípios, o plano de ação e ainda outras informações no Blog: http://tratadodeea.blogspot.com/ Último acesso em 18 de Julho de 2016.

\section{AS ESTRATÉGIAS TEÓRICO-METODOLÓGICAS UTILIZADAS E POSSÍVEIS. OU DIZENDO DE OUTRA FORMA, OS JEITOS DE FAZER AS COISAS.}

As estratégias surgiram no contexto das interações, emergindo uma mistura muito proveitosa, em um contínuo circular de fazer - refletir - estudar - refletir dialogar - refletir - fazer novamente, em um ir e vir hermenêutico / dialético / dialógico, a partir de duas hipóteses:

(a) que a USF pesquisada pudesse vir a ser um lugar de interações dialógicas na perspectiva das comunidades aprendentes;

(b) que, de modo geral em todo o país, as USF pudessem ser consideradas, talvez, como "comunidades adormecidas", que venham a despertar com a práxis (ação+reflexão) multidisciplinar coeducativa; ou seja, com a aprendizagem permanente, que deve contribuir para as transformações socioambientais e uma nova ordem social mundial.

A expressão popular "tudo junto ao mesmo tempo agora" apresentada por Guimarães (2008, p. 13) é interessante para resumir como se realizou este trabalho, em um contínuo circular, tal como sugerido no Quadro II $^{9}$ :

A Pesquisa-Ação-Participante (PAP) ou Pessoas que Aprendem Participando (igualmente PAP) serviu como "coluna

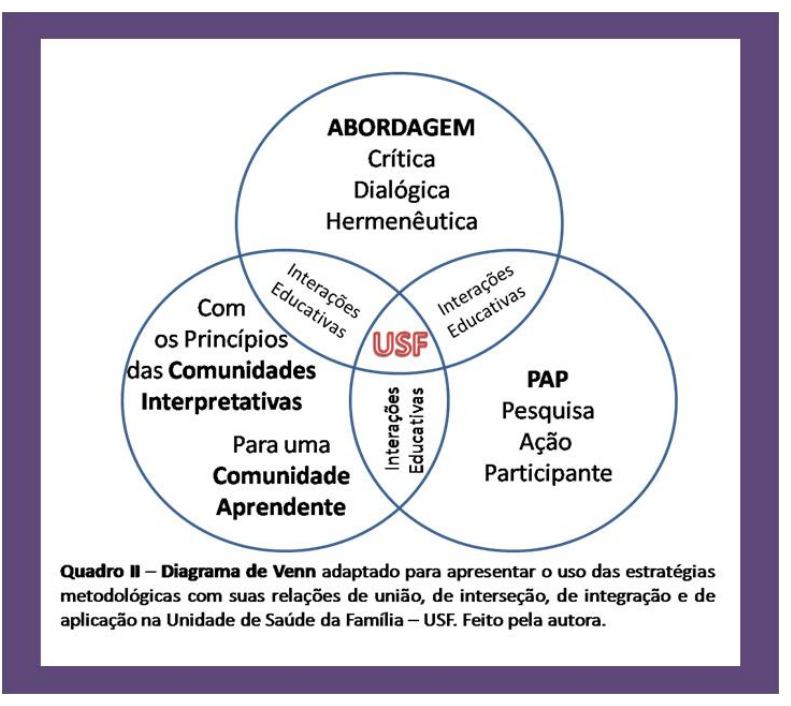
vertebral" para o trabalho, porque, para mim, fica praticamente impossível não a considerar, se quisermos atuar com os princípios das comunidades interpretativas para a lida com a dimensão educativa de uma comunidade aprendente. Numa adaptação feita à síntese do conceito PAP, elaborada por Fals Borda, em 1983 (VIEZZER, 2OO5, p. 282), essa estratégia pode ser assim descrita:

\footnotetext{
${ }^{9} \mathrm{O}$ aprofundamento das estratégias metodológicas consta no texto original da monografia de pesquisa.
} 
"Trata-se de uma metodologia dentro de um processo vivencial, um processo que inclui simultaneamente educação de pessoas de todas as idades, pesquisa científica e ação social ou política, e no qual se consideram como fontes de conhecimento: a análise crítica, o diagnóstico de situações e a prática cotidiana".

Com relação à estratégia metodológica das comunidades interpretativas, foi possível perceber o encaixe de todas as interações coeducativas nos três princípios dessa estratégia apresentados por Avanzi e Malagodi (2005): 1) o princípio do diálogo, 2) em um espaço comunicativo horizontal e 3) com o esclarecimento das intenções, crenças e expressões dos participantes, tudo isso necessário para que a coletividade daquela USF tivesse maiores chances de "vir a ser" uma comunidade aprendente ao longo do tempo (AVANZI; MALAGODI, 2005, p. 95).

Por sua vez, a dimensão educativa das comunidades aprendentes (no âmbito da referida USF) pode ser identificada na afirmativa de Brandão (2005) de que "aprendemos com o conviver com os mundos de nosso mundo". $\mathrm{O}$ autor assegura que todo e qualquer momento é potencial de aprendizagem; e que, desse modo, a educação se liberta dos muros escolares para ser identificada em todo e qualquer outro ambiente, no dia a dia, com "cada troca de palavras, cada troca de gestos, cada reciprocidade de saberes e de serviços com uma outra pessoa" (BRANDÃO, 2005, p. 86).

\footnotetext{
"Do lar ao círculo mais amplo de parentes e de vizinhos, deles aos pequenos grupos sociais em que vivemos a nossa vida de todos os dias, de um time de futebol a uma igreja, a uma equipe de trabalho, a uma outra, da associação de moradores do bairro, estamos sempre envolvidos em e participando de pequenas e médias comunidades de vida e de destino. De lazer, de vocação, de trabalho, de participação social. De conviver entre gestos que dão sentido à família, ao grupo, à equipe, mas que cada um a seu modo, são também protagonistas de cenas e cenários do ensinar e aprender" (BRANDÃO, 2005, p. 87).
}

Para a abordagem crítica, segundo Loureiro (2005) "as metodologias que classicamente expressam uma perspectiva crítica em geral são as de cunho participativo: "pesquisa-ação-participante, pesquisa-participante, investigação-ação, investigaçãomilitante etc." No Brasil, estas variações se traduziram na utilização intensa da Pesquisa Participante, tradicionalmente vinculada à educação popular, e na PAP, denominação comum entre educadores ambientais (LOUREIRO, 2005, p. 328).

Sobre a dialogicidade, coerente aos fundamentos freirianos, Logarezzi (2010) afirma que o qualificativo dialógico indica "que no fundamento do processo educativo estão a incompletude humana e a tomada de posição frente ao real", como ciência do ser 
e como alicerce para a educação; bem como nesse mesmo processo está manifesto o diálogo "como capacidade humana mediadora do processo de se educar e de se refazer no mundo e com as outras pessoas". Diálogo que se manifesta "entre sujeitos dispostos à humanização e à coerência entre o que se faz e o que se fala cotidianamente" (LOGAREZZI, 2010, p. 13 e 14).

E quanto à hermenêutica, compreendo que todo o trabalho de pesquisa esteve à luz da "interpretação e da compreensão", para resumir muito um conceito difícil de ser apreendido. Há um precioso esforço dos autores Carvalho e Grün (2005) para desvelar alguns dos véus contidos neste conceito. Eles afirmam que a hermenêutica trata "de evidenciar os horizontes de sentidos histórico-culturais que configuram as relações com o meio ambiente para uma determinada comunidade humana e num tempo específico". Logo, a EA como prática de interpretação, desvelo e produção de sentidos "estaria contribuindo para a constituição de um horizonte compreensivo das relações sociedadenatureza", ao abandonar "um conceito realista ou naturalista de meio ambiente, onde este é reduzido às suas condições e leis físicas de funcionamento". (CARVALHO; GRÜN, 2005, p. 180).

Por fim, a revisão bibliográfica implicou compreender a complexidade contida, sobretudo, no binômio intergeracionalidade-sustentabilidade, além do aprofundamento nas estratégias metodológicas utilizadas ou possíveis. Sobremaneira contribuiu ao entendimento da sustentabilidade como resultado de um contínuo dialógico entre e intrageracional, responsável por forjar novas comunidades que reflitam em longo prazo uma reumanização e outro mundo. Em outras palavras, para forjar sociedades sustentáveis abrigadas por um tecido social horizontal e plural, materializadas nas mais variadas formas de comunidades de viventes felizes.

\section{CONCLUSÕES INCONCLUSIVAS, OS PRINCIPAIS DESAFIOS PARA SEGUIR ADIANTE...}

Seguindo com a arquitetura da EA crítica, capaz de vir a revolucionar o modo de intervir com/na realidade, tentando criar outros modos de vida em trajetórias que pode nos levar a sociedades sustentáveis. Importa menos gerar alguns tipos de conflitos de expectativas, assim como alguns vivenciados, na medida em que não foi prescritivo, 
com receituários de novos modelos comportamentais. Mas que procure promover, sobretudo, a abertura para o novo, ao acolher quaisquer diferenças, incluindo a idade.

Por esse ângulo, seguindo com a ressignificação do diálogo, passo a passo, tendo a intergeracionalidade como um ingrediente muito especial, o que poderá ser o elemento estruturador de peculiares experiências de comunidades aprendentes com o objetivo de construir sociedades sustentáveis. Cujas identidades sejam evidentes através da equidade, da justiça social e da solidariedade, da qualidade das relações estabelecidas, além do respeito aos direitos humanos e aos direitos de todos os demais seres vivos.

Considero que a investigação naquela USF teve o propósito de semear o processo, acenando positivamente para essa ressignificação. Mas dependerá de continuidade, quer seja animada por novas pesquisas acadêmicas interdisciplinares no campo da EA, da Gerontologia e de outras áreas de estudo, quer seja pautada por políticas públicas ou, ainda, iniciativas no campo da educação popular, geralmente promovidas por organizações não governamentais.

Contudo, permanece o desafio para estabelecer um espírito coletivo, onde seja prioritário o respeito para com os saberes inquestionáveis das pessoas mais velhas, e para que o diálogo tenha maiores chances de emergir para a reconstrução desses saberes, em um local onde ficaram evidentes as diferenças socioeconômicas e culturais. Naquela USF perceberam-se dois conjuntos distintos: as cuidadoras de jaleco branco, que estudaram e "sabem" dar atenção aos usuários; e as/os "carentes" em múltiplos sentidos, que requerem cuidados especiais, pertencentes às classes menos favorecidas.

Para as intervenções que envolvam a intergeracionalidade, agregam-se a essas diferenças socioeconômicas e culturais, aspectos como preconceitos e estigmatizações atribuídos a quaisquer gerações. E para a velhice há um agravamento típico das sociedades que supervalorizam as gerações jovens, diferentemente de sociedades onde é possível ver a presença não só da população idosa nas ruas, quanto de pessoas inseridas no mercado de trabalho, que estão na faixa de idade madura.

Depreende-se da experiência investigativa, ainda, que é necessário seguir adiante com o exercício coeducativo intergeracional nos mais variados espaços educadores abertos. Em práticas de educação popular como centros comunitários, salas de educação de jovens e adultos (EJA), as agremiações de caráter religioso ou não, sindicatos, etc., procurando acolher as diferenças e não permitindo que a idade seja um empecilho ou 
estorvo. Ao contrário, com a recuperação, a valorização e a ressignificação da memória e da história oral, para o enraizamento dessas ações. Afinal,

\section{[...] ninguém amadurece de repente, aos 25 anos. A gente vai amadurecendo todo dia, ou não. A autonomia, enquanto amadurecimento do ser para si, é processo, é vir a ser. Não ocorre em data marcada. É neste sentido que uma pedagogia da autonomia tem de estar centrada em experiências estimuladoras da decisão e da responsabilidade, vale dizer, em experiência respeitosa da liberdade (FREIRE, 2002, p. 67).}

E levar em conta a dimensão do tempo sempre! Só respeitando este "Senhor dos Universos" para fazer alguma diferença na solução dos conflitos e no desenvolvimento da afetividade ao longo do processo, nas relações eu-tu e eu-outro, qualquer outro ser vivo, implicando ações afetivas e significativas com o meio ambiente, em contraponto às relações utilitárias dos recursos naturais.

Mesmo que esse Senhor já tenha dado sinais mais que evidentes de urgência para uma transformação nas estruturas socioeconômicas e não apenas nas suas bordas. O tempo é indubitavelmente importante para tudo na Vida! E particularmente para os diálogos e a coeducação para a sustentabilidade, tendo em vista a sua permanência; para que uma coletividade - ao desenvolver o sentido individual e coletivo de pertencimento - vivencie conjuntamente esse desafio, protagonizando sua autonomia. Num período longo para seguir com a práxis, com os princípios do cuidado, da precaução e da prevenção. Porque, afinal, sustentabilidade é "tudo", como disse aquela coparticipante.

Para muitas/os de nós, ficou claro que a sustentabilidade não é uma coisa ou outra, pois da forma como vimos pensando e sentindo, trocando e refletindo essa troca, sustentabilidade estará sendo esse tudo, sempre! Exigindo a percepção de que estamos inseridas/os em contextos desafiadores, numa arena de disputas que envolvem os poderes da economia e da política, em cujos cenários nos tornamos agentes ou pacientes a depender de como encaramos e reagimos às diferentes leituras, com seus vieses ideológicos, de uma única ${ }^{10}$ crise socioambiental muito complexa e planetária.

A partir do texto coletivo apresentado no Quadro I, foi possível construir uma simples definição do conceito sustentabilidade, também como resultado intergeracional da investigação. Algo que, talvez, eu não fosse capaz de elaborar sozinha com palavras simples em uma frase tão curta: 
"Sustentabilidade é tudo vivendo em harmonia e em equilibro, essenciais para uma vida feliz, com qualidade e na observância dos direitos fundamentais à Vida, e a tudo que seja necessário à permanência dos seres vivos, humanos ou não, na face da Terra”.

\section{REFERENCIAS}

AVANZI, Maria Rita; MALAGODI, Marco As. Comunidades interpretativas. In: Encontros e Caminhos: formação de educadoras(es) ambientais e coletivos educadores/ Luis Antonio Ferraro Júnior, organizador - Brasília: Diretoria de Educação Ambiental, 2005, p. 93-102. Disponível em: http://www.mma.gov.br/estruturas/educamb/_arquivos/encontros.pdf . Acesso em $20 \mathrm{de}$ junho de 2016.

BOFF, Leonardo. "Sustentabilidade: tentativa de definição". In: leonardoBOFF.com, janeiro de 2012. Disponível em: https://leonardoboff.wordpress.com/2012/01/15/sustentabilidade-tentativa-de-definicao/ Acesso em 20 de junho de 2016.

BRANDÃO, Carlos R. Comunidades aprendentes. In: Encontros e Caminhos: formação de educadoras(es) ambientais e coletivos educadores/ Luis Antonio Ferraro Júnior, organizador - Brasília: Diretoria de Educação Ambiental, 2005, p. 83-91. Disponível em: http://www.mma.gov.br/estruturas/educamb/_arquivos/encontros.pdf . Acesso em 20 de junho de 2016.

CARVALHO, Isabel Cristina Moura; GRUN, Mauro. Hermenêutica e educação ambiental. In: Encontros e Caminhos: formação de educadoras(es) ambientais e coletivos educadores/ Luis Antonio Ferraro Júnior, organizador - Brasília: Diretoria de Educação Ambiental, 2005, p. 175-187. Disponível em: http://www.mma.gov.br/estruturas/educamb/_arquivos/encontros.pdf . Acesso em 20 de junho de 2016.

CAVALCANTI, Robinson. "Livrai-nos do (capitalismo) mal. Os valores do reino versus os modos iníquos de produção". Revista Ultimato, Viçosa, MG, Editora Ultimato, março-abril de 2004.

COSTA LIMA, G. F da. "Educação ambiental crítica: do socioambientalismo às sociedades sustentáveis". Revista Educação e Pesquisa, São Paulo, v.35, n.1, p. 145163, jan./abr. 2009. Disponível em: http://www.revistas.usp.br/ep/article/view/28185 . Acesso em 20 de junho de 2016.

FERRIGNO, José Carlos. Co-educação entre gerações. Petrópolis, Rj: Vozes; SP: SESC, 2003.

FREIRE, Paulo. Pedagogia da autonomia. Saberes necessários à prática Educativa. Publicação Original: 1996. Ano de Digitalização: 2002. Disponível em http://plataforma.redesan.ufrgs.br/biblioteca/pdf_bib.php?COD_ARQUIVO=17338 Acesso em 20 de junho de 2016.

Pedagogia da esperança. Um reencontro com a pedagogia do oprimido. São Paulo, $17^{\circ}$ Edição, Paz e Terra, 2011.

GADOTTI, Moacir. Educar para a sustentabilidade: uma contribuição à década da educação para o desenvolvimento sustentável. São Paulo, $2^{\circ}$ Edição (Série Unifreire; 
2), Editora e Livraria Instituto Paulo Freire, 2012. Disponível em: http://acervo.paulofreire.org:8080/jspui/bitstream/7891/3080/1/FPF_PTPF_12_077.pdf . Acesso em 20 de junho de 2016.

GRAJEW, Oded. "O que é (e o que não é) Sustentabilidade", Jornal Folha de SP, publicado em 7/05/ 2013. Disponível em: http://www3.ethos.org.br/cedoc/o-que-e-e-oque-nao-e-sustentabilidade/\#.V2QusrvhDI . Acesso em 20 de junho de 2016.

GUIMARAES, Mauro (org). Caminhos da Educação Ambiental. Da forma à ação. $3^{\circ}$ Ed. Papirus Editora, 2008.

HUPFFER, Haide Maria. "Degradação ambiental e consciência da história efeitual: contribuições de Hans-Georg Gadamer ao diálogo intergeracional". Revista Espaço Acadêmico, Universidade Estadual de Maringá, PR, v. 11, n. 131, p. 109-119, 2011. Disponível em: http://www.periodicos.uem.br/ojs/index.php/EspacoAcademico/article/view/13722/898 9 . Acesso em 20 de junho de 2016.

LADEIRA, Francisco Fernandes. "A Espetacularização da Realidade", Jornal de debates do Observatório de Imprensa, Universidade Estadual de Campinas (Unicamp), SP, edição 854, junho de 2015. Disponível em: http://observatoriodaimprensa.com.br/jornal-de-debates/a-espetacularizacao-darealidade/ Acesso em 20 de junho de 2016.

LOGAREZZI, A. M. J. "Educação ambiental em comunidades de aprendizagem: uma abordagem crítico-dialógica". In: Reunião Anual da ANPED, Caxambu, RJ, p. 13-14, 2015. Disponível em: http://33reuniao.anped.org.br/33encontro/app/webroot/files/file/Trabalhos\%20em\%20P DF/GT22-6130--Int.pdf . Acesso em 20 de junho de 2016.

LOUREIRO, Carlos Frederico B. Teoria Crítica. In: Encontros e Caminhos: formação de educadoras(es) ambientais e coletivos educadores/ Luis Antonio Ferraro Júnior, organizador - Brasília: Diretoria de Educação Ambiental, 2005, p. 323-332. Disponível em: http://www.mma.gov.br/estruturas/educamb/_arquivos/encontros.pdf . Acesso em 20 de junho de 2016.

OLIVEIRA, Sara Monise de. Educação ambiental com jovens e adultos: espaços comunitários, de trabalho e de formação profissional. In: Cadernos do Cescar Educação Ambiental - Caderno 3 - Sistematização das interações educativas das pessoas que aprendem participando (2007- 2008) - Projeto Viabilizando a Utopia (ViU) 2005-2011. Organizado por Isabel Georgina Patronis Dominguez, Edna Kunieda, Sara Monise de Oliveira, Natália Salan Marpica, Silvia Aparecida Martins dos Santos e Haydée Torres de Oliveira. - São Carlos: Gráfica e Ed.Futura, 2011. Disponível em: http://www.academia.edu/1849497/Cadernos_do_Cescar_Educa\%C3\%A7\%C3\%A3o_ Ambiental_Caderno_3_Acesso em 20 de junho de 2016.

VIEZZER, Moema L. Pesquisa-ação-participante (PAP). In: Encontros e Caminhos: formação de educadoras(es) ambientais e coletivos educadores/ Luis Antonio Ferraro Júnior, organizador - Brasília: Diretoria de Educação Ambiental, 2005, p. 277-294. Disponível em: http://www.mma.gov.br/estruturas/educamb/_arquivos/encontros.pdf . Acesso em 20 de junho de 2016. 
AMBIENTE \& EDUCAÇÃO

ISSN- 1413-8638

E-ISSN - 2238-5533

v. 22 , n. 1, p. 40-60, 2017

WHITAKER, Dulce C. Andreatta. Envelhecimento e poder. A posição do idoso na contemporaneidade. Campinas, SP. Editora Alínea, 2007. 